tissue, and as far as the patient is concerned we have a sterile field and wound. I strongly commend this simple expedient. I have elsewhere described some towel clips constructed to my requisition by Messrs. Mayer, Meltzer, and Co., one of the chief objects of which was to bring about the same result.

Bearing also on the subject of primary union of wounds, I would like to call attention to a plan adopted recently on my own initiative in regard to the question of operative skin preparation and treatment. This method is based upon the phenomenon, which I think cannot be denied, that all clean wounds heal much better if kept dry, and that moisture undoubtedly favours or provokes inflammation. No one would think of applying a moist dressing to, or keeping wet, a clean wound if healing by first intention were desired, for such an action would court disaster. To operate on a sodden skin would be folly, and I think a good deal of the trouble experienced with wounds, even after the most careful preparation, is due to previous humidity; and to my mind there is no more culpable agent provocateur than the favoured and time-honoured protective compress. Probably much of the failure in, and past difficulty in explaining the state of, operative wounds finds its elucidation here. This old and favourite method.might be called the wet compress method (lint, protective and wool) as opposed to the one to be described - namely, the dry compress method. I believe much of the value and credit gained by iodine applications to be due not only or necessarily to its hyperæmic and bactericidal properties, butalso to the desiccating properties of this preparation. Water being a sine quâa non for the life of vital organisms, and therefore of bacteria, and dryness spelling death or quiescence, it would appear that the day of moist applications is over, and that no compress or dressing that includes protective (moisture retaining) should henceforward be considered. Pathological kncwledge and surgical experience condemn such. The dry method is as follows. The skin is washed by ether soap (never scrubbed), then gone over with turpentine, followed by spirit of biniodide of mercury. Now come the chief modifications. The skin is covered by sterilised talcum toilet powder; any of these may be used, as the preparations of Parke Davis, Colgate, Sewar, \&c. These powders are free from irritating antiseptics, and have valuable desiccating properties. The powder is now gently rubbed into the skin by a sterile piece of wool, after which the part is covered by a thick layer of powder, and the whole region covered by a dry sterile compress, which is bandaged on, but mind, no protective of any kind to keep the skin sodden or retain moisture, and therefore invite bacterial activity and disaster. At the time of operation the skin presents an ideal appearance, for it is dry, and, I think, as a fact and for this reason gives gratifying results; at least, such has been my experience so far. At the end of the operation the line of incision is covered with a thick layer of powder; incidentally this prevents adhesion of wound to dressings, and thereby obviates this source of irritation to the patient as well as to the wound. On subsequent days powder is applied again as required. I have noticed during the adoption of this technique not only absence of redness at the site of incision but also at the sites of the suture punctures. Perhaps a combination of this powder method and iodine might give even better results. But so far I am satisfied.

I would, therefore, lay emphasis on the dry method of preparing the skin, the avoidance of anything that will render moistness inevitable, especially the old and bad protective (oiled silk, gutta-percha tissue, \&c.) compress application. The results so far obtained promise well for the future and are most encouraging.

I am, Sir, yours faithfully,

G. S. Thompson, F.R.C.S. Eng.

Kimberley, S. Africa, Mairch 10th, 1913.

\section{A DANGER TO HEALTH IN THE NEW FOREST.}

To the Editor of THE LANCET.

SiR,-My attention has been called to an article with the above title which appeared in THE LANCET of March 29th, p. 910, that does grave injustice to the work of the medical officer of health for Ringwood, Mr. Charles E. Blackstone, and also to that of the medical officer of health for the county, Dr. Robert A. Lyster, and to the rural district council. Anyone-reading - your remarks would conclude that a plague spot, indeed, has been discovered, and that it was administered by a most careless local authority, assisted by thoroughly incompetent officials.

The report of the medical inspector of the Local Government Board, Dr. H. A. Macewen, upon which your remarks are based, is an unfortunate and misleading one, and contains many apparent errors in the statement of facts, concerning which it is difficult to understand how mistakes could arise. As, however, correspondence is going on between the Ringwood district council and the Local Government Board upon this report, I will not attempt to dealt with that matter here, but will instead briefly state what actually occurred. Before doing so I may as well freely admit that the water-supply of Ringwood is derived from shallow wells. As the result of examinations from time to time by successive medical officers of health these wells have not been unfavourably reported on, and the district council have given special attention to endeavour to preserve them from surface pollution. There has been nothing in the vital statistics of the district to cause concern, and though a public water-supply is probably an advantage, provided that it is derived from absolutely reliable sources, yet there have been no signs until recently that the ratepayers would sanction such a course.

Coming now to the epidemic of enteric fever last year, the first notifications reached the medical officer of health on August 13th, the cases then being of a mild type, and, I believe, entirely confined to children. The earliest case of the commencement of illness discovered here was on July 26th. We can find no trace of a case on July 18th as mentioned by you. At all events, no case was notified until August 13th, no doubt because the disease could not be clearly diagnosed before then. On August 19th the district council met, and first heard of the outbreak. They consulted with their medical officer of health and with Dr. J, Gott, Poor-law medical officer, and upon their advice decided to at once engage nurses to work amongst the patients at their homes. The question of an isolation hospital was discussed, but temporarily allowed to remain in abeyance, as doubt was expressed as to the parents consenting to the removal of their children. It was arranged, however, that the health committee of the district council should be strengthened, and be summoned directly the epidemic showed signs of increasing. This committee met on August 21st and many times afterwards, and at once decided to open an isolation hospital, which was done on August 27th, or eight days after the council first heard of the outbreak, and 14 days after the receipt of the first notification. You refer to this hospital as being "of an unsatisfactory kind." It consisted of a fair-sized farmhouse in an open situation, with lofty rooms. A large Doecker hut was added as an annexe and a day room for convalescents was built of wood and galvanised iron in addition. It is a matter of opinion, of course, but most competent judges thought the hospital accommodation fairly good and decidedly creditable under the circumstances. On August 29th a letter was received by the clerk to the district council from the Local Government Board asking that the former body would request their medical officer to submit a report upon the epidemic. The next meeting of the council took place on Sept. 2nd, when this letter came before them and was dealt with. But on August 31st, late at night, Dr. Macewen appeared upon the scene, full of surprise that the desired report had not been received. He called upon the medical officer of health, who, late though it was, was extremely busy, and expressed his views in such language that a speedy termination of the interview was brought about. He also called on the chairman, the vicar of the parish, who no doubt received him with every attention, but as a clergyman with a heavy Sunday's duty before him the next day could hardly be expected to unduly prolong the conversation.

As to the cause of the epidemic, directly its presence was made clear every step was taken to try and establish from whence it originated. Water, milk, school contact, and so on, were all investigated in turn, Dr. Lyster, county medical officer of health, rendering the greatest assistance in the endeavours that were made. In pursuit of this object he had been in conference with Mr. Blackstone on August 31st, and had borrowed the written data for consideration until Sept. 2nd, when he returned it. This was the reason why this data was not available for Dr. Macewen's perusal on the evening of the same day, as he perfectly well knew. Although Dr. Lyster returned the papers on Monday, 
Sept. 2nd, it seems singular, but it is a fact, that Dr. Macewen never again asked to see them. It is also the case that he never once interviewed the district council, though they would have been pleased to see him. He casually met two members by chance, of whom I was one, and had a few words of conversation of quite an unofficial character, and, as already stated, he called upon the chairman. Dr. Macewen has expressed the opinion that the cause of the epidemic was the stream you allude to. I have been through his evidence most carefully, comparing it with reliable data, and as far as I am able to judge his theory and his evidence tumble to pieces when tested. In reports submitted to the district council, Mr. Blackstone states that, though the matter is not free from doubt, he believes that the strongest evidence points to the epidemic having originated from ice-cream supplied at school treats, the subsequent cases being contacts, and the ice-cream maker an intermittent carrier. 1 understand that Dr. Lyster also favours this view, though investigations are still going on in connexion with it.

I hope in justice to two capable and most assiduous medical men, if not to the district council, you will take steps to correct the most unfortunate impression conveyed to anyone reading your article who was ignorant of the real facts of the case.-I am, Sir, yours faithfully,

\section{HOWARD TOZER,}

Vice-chairman, Ringwood Rural District Council.

Ringwood, April 6th, 1913.

\section{QUIS CUSTODIET IPSOS CUSTODES? \\ To the Editor of THE LANCET.}

SIR, - A few days ago I sent a patient with somewhat obscure symptoms to have his blood examined at a wellknown clinical laboratory in London, and received back a report which strongly suggested that he was suffering from an early stage of pernicious anæmia. In view of the importance of the matter I decided, before starting him on a course of arsenic, to obtain further corroboration of the diagnosis, and accordingly sent him to another laboratory in London for a second blood examination. A report followed which entirely negatived the diagnosis of pernicious anæmia. Only three days elapsed between the two examinations; during that time there was no alteration in the patient's symptoms and he had no special treatment. In each case the blood was taken at the laboratory, and at about the same hour of the day. I append the chief points in the two reports. It is upon facts such as these that the unfortunate physician has nowadays largely to rely for his diagnosis and his treatment. I need only add that I had a third examination made with the greatest care by a hospital colleague, and the results obtained differed materially from those given in both the previous reports, though they approximated more nearly to those in the first.

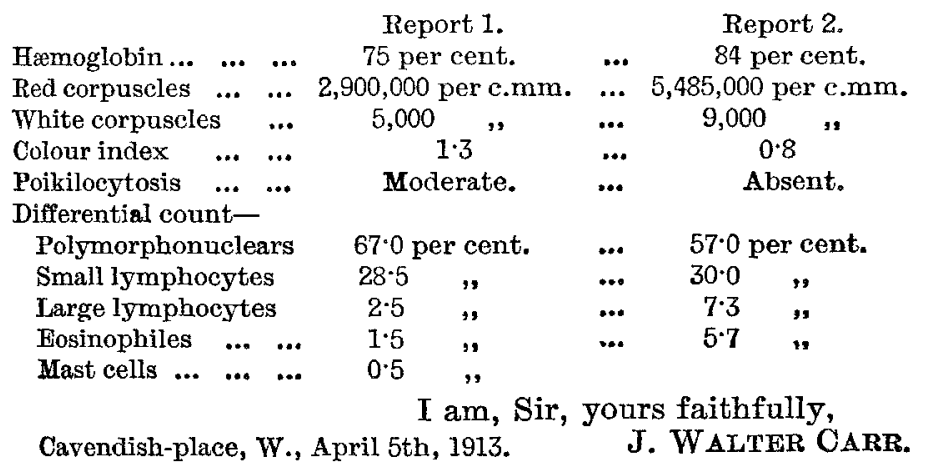

\section{RECOVERY IN ACUTE TUBERCULOUS PNEUMONIA.}

To the Editor of THE LANCET.

SIR,-I read with some interest Dr. S. N. Galbraith's paper on "Acute Tuberculous Pneumonia: Recovery" in to-day's issue of THE LANCET. I am of opinion that such cases are far from uncommon, though I would suggest that the prognosis is never really good.

The following is a good example of this condition. The patient, a youth 16 years of age, was admitted to the Ayrshire Sanatorium on August 16th, 1910. His illness commenced 16 weeks before admission and followed directly on over-exertion, produced by a long bicycle ride; he was, however, walking two or three miles every day until his admission to the sanatorium, though unable to follow his occupation of coalminer; during this period he was suffering from heavy night sweats. On admission he was running a temperature varying from $101^{\circ} \mathrm{F}$. at night to $99^{\circ}$ in the morning, which fell to normal in eight days following upon rest in bed and silence, and after that was never above the normal, his rectal temperature before rising averaging 97. $7^{\circ}$. He had four ounces of sputum on admission containing tubercle bacilli. Physical examination revealed a condition of massive consolidation, apparently involving the whole of the left lung; there were also signs of softening at the right apex. He remained in the sanatorium five months, during which time he was able to do fairly heavy work in the garden, such as digging and wheeling barrows, without producing symptoms of auto-inoculation; he gained $19 \frac{1}{4} \mathrm{lb}$. in weight, and looked and felt quite well. His sputum was reduced to two or three pieces, and bacilli were not found when last examined. The condition at the left side of the chest was practically unchanged; the lung was apparently quite solid from apex to base. He returned home on Jan. 13th, 1911, and worked in a factory until April, 1912. His lung, I believe, then broke down, and he died on June 5th, 1912.

'The following is another example. The patient, a young' man 20 years of age, was admitted on Sept. 9th, 1912, and discharged on Nov. 1st. The commencement was somewhat different from that in the last case. He described himself as having been quite well until April, 1912 ; just before this he had complained of a little cough and some weariness. He then went home for a week-end, and owing to the coal strike was compelled to walk eight miles; at the end of this walk he was completely done, and his mother informed me that when he reached home he looked like corpse. He became delirious after the walk, and remembered nothing for a month; he was thought to have acute pneumonia, and had consolidation of the whole of the right lung: At the end of a month he began to improve, and was sent to the sanatorium some months later. On admission he was afebrile, the pulse was usually over 100 , and respirations 24 ; his breath was rather short. His temperature remained normal until he had a dose of Spengler's I.K., 0.2 c.c. of 1 ire 100,000, which immediately sent it up and increased his sputum and made him generally ill. The temperature fell immediately after another dose of $0 \cdot 2$ c. c. of 1 in $10,000,000$. He then went home. On leaving, the right side of the chest was still quite solid. The sputum on admission and on discharge contained abundant tubercle bacilli. I saw his medical adviser three days ago, and he tells me that the patient is improving and that his pulse has dropped to 96 .

I have at present in the sanatorium two similar cases. One of them is interesting from the retrospective standpoint, for in his case the pneumonic consolidation occurred ten years ago. At that time he was in bed three months and was off school 14 months. Since then he remained well until November, 1912, when he had a fresh outbreak. He was only admitted to the sanatorium on March 28th last, and his condition is quite good. The upper lobe on the left side shows extensive consolidation. Like the majority of these cases, he has very little sputum, but what there is is loaded with tubercle bacilli. As he has had a cough ever since his first attack, he would seem to have been very dangerous to his neighbours.

With regard to the above examples I should like to point out that both the two severe cases resulted from over-exertion in the early stage of pulmonary tuberculosis ; secondly, that it was probably the massiveness of the consolidation which put a period to the acute symptoms, the massive consolidation greatly limiting movement, and at the same time greatly reducing the blood-supply. Furthermore, I am inclined to think that it is the massiveness of the consolidation which is the ultimate undoing of such cases. From experience $I$ an led to believe that consolidation is the most difficult sondition to cure of all the complications of phthisis, its seriousness depending on its extent. Where massive, tuberculin is unlikely to be of great benefit, though if given carelessly may well produce such a condition, for any immunity acquired by the administration of tuberculin is of necessity transitory, and efforts to break down and cause exfoliation of these masses are liable to produce calamitous results.

Personally, to me there seems no justification for giving 